\title{
Development of Fuel Maps in Hexadecimal Format for Reduction of NOX Emissions and Application in Real HCCI Engine
}

\author{
Michal Puškár ${ }^{1, *}$, Melichar Kopas ${ }^{1}$, Dušan Puškár ${ }^{1}$ \\ 1 Department of Engineering for Machine Design, Automotive and Transport, Letná 9, 04001 Košice, Slovak republic
}

\begin{abstract}
The newest generation of the electronic control systems, which are determined for the combustion engines, is characterised by a complex structure of the control algorithm. Modification of these systems is performed using a data field editing in order to reach the maximal output parameters. The active algorithms of the control units gained a remarkable participation and mutual relation. The control software is operating with the numerical combinations, which are described in a hexadecimal format. There were suggested various types of the fuel maps and they were tested by means of measurement realised during four sequences of a powerful engine. At the same time there were also monitored, during all the operational measurements, the working parameters using a data link connection. The results obtained from measurement that were performed at the complex dynamometric station confirm a relevant contribution in the area of the engine power output characteristics utilizing the developed hexadecimal matrix. A typical characteristic of the engine torque demonstrates a continuous increase of the torque values within a wide range of the engine speed.
\end{abstract}

Keywords: electronic control unit, fuel maps, engine characteristics.

\section{Introduction}

The present control units of powerful single-track vehicles are distinguished not only by the control algorithm structures but also by determined modification software products. A modification of motormanagement function is performed using an editing of data fields predominately in the case powerful combustion engines. A replacement of some electronic component in a control unit printed circuit is required only in a low number of specific situations. More frequently there is an exchange by unoriginal control units made by specialised companies dealing exclusively with motorsport [1]. The most of produced motormanagement systems for racing motorcycles is designed with a high-level requirement concerning a velocity and a range of data processing. These motorbikes are not equipped with specialised systems developed for comfort and safety conditions because their operation is focused on maximum power output parameters above all.

Active algorithms of control units have got a notable complicity and a mutual interrelation. The control of motormanagement is specified by a processor code, which determines concrete activities of a control program. A control unit microprocessor uses a combination of the elementary binary digits 0 and 1 . The control software operates with a numerical combination in the hexadecimal 
format in order to control the individual activities. The individual data fields stored in a given control unit memory are determined by means of data described in the hexadecimal format. It is necessary to know a relationship between the decimal system (dec.) and the hexadecimal system (hex.) $[2,3]$. The control program ECU applies the hexadecimal format consisting of 16 symbols, i.e. the capital alphabetical letters from A to $F$ and the numbers from 0 to 9 (Fig.1).

A transformation from the hexadecimal format to the decimal data using the editing software is important at an adjustment of basic data fields for a fuel injection, an ignition advance or input data of temperatures. Many professional modification software products offer this transformation possibility by means of simple setup. A calculator of operational system enables a simple help for transformation if a menu bar does not offer it. The more sophisticated modification programs enable an exact selection of function data fields from the EPROM memory and their following proper modification. Each of necessary information unavoidable for a proper and quick reaction of motormanagement, is addressed so as the control unit can operate only with correct data. The concrete address of data information is determined in a data matrix by the given row and column (Fig.2). These addresses are defined in the hexadecimal system.

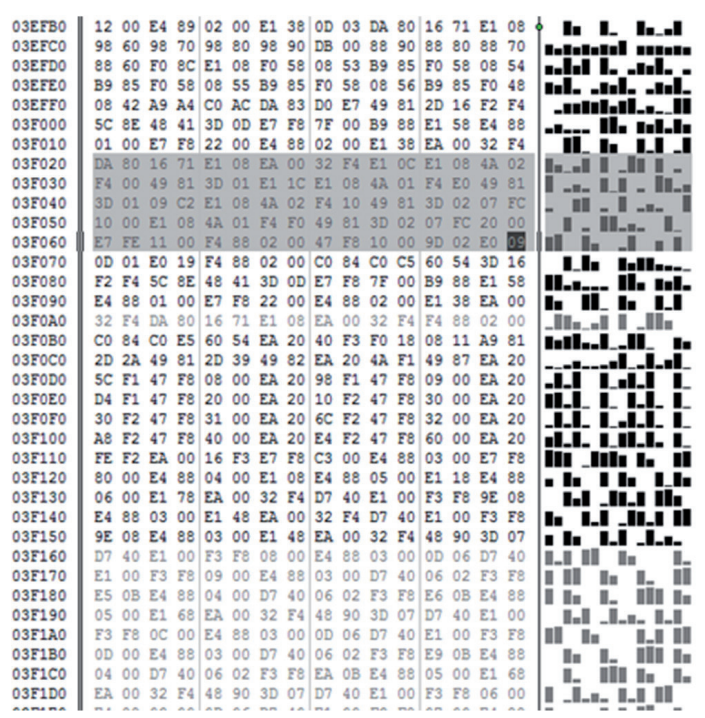

Fig. 1: Data structure in hexadecimal (hex.) format.
A meeting of checksum is a very important factor for modification of control program. This checksum serves predominately for the integrity control of data stored in the EPROM/EEPROM memory. A checksum algorithm enables to verify used data [4].

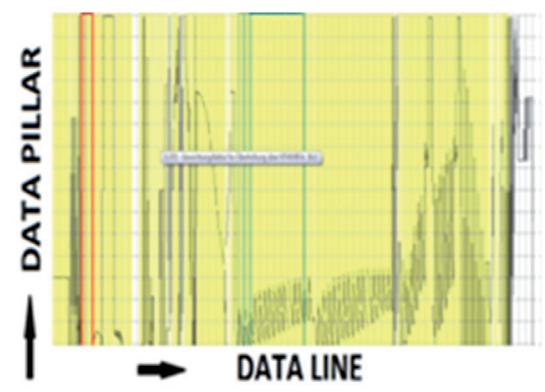

Fig. 2: Two-dimensional presentation of data fields.

Producers of serial control units use this checksum for an access restriction into data fields as well. An assembly of optimal data fields is important for the improvement of power output parameters. The individual data fields correlate each other and they are influenced mutually. It is important a relation between input and output motormanagement parameters. The control unit enables to correct these interrelations and to modify output values to a certain extent. The motormanagement can adjust output values according to the mutual relations, which are defined in two-dimensional or three-dimensional data fields [5].

\section{Experimental model and devices}

In order to perform modification of data fields it was applied specialised software. A sophisticated possibility of the data field editing with an active relation to sensors and active members, taking into consideration their functionality, was enabled by means of user operating environment for multiple software products.

The exact setting of control parameters and control of the whole motormanagement system functionality require an application of control measuring apparatuses and devices. A proposal of data fields was performed at a racing motorcycle. The applied driving unit was four-stroke ignition engine with the displacement $449 \mathrm{~cm}^{3}$. The specifications of the engine used in the test are shown in Table 1. 
Tab. 1: Technical Parameters of the Tested Engine.

\begin{tabular}{|l|l|}
\hline Type & $\begin{array}{l}\text { Single-cylinder, a four-stroke combustion } \\
\text { engine, DOHC four valve, liquid cooled }\end{array}$ \\
\hline Displacement & $449.0 \mathrm{~cm}^{3}$ \\
\hline Bore and Stroke & $96.0 \times 62.1 \mathrm{~mm}$ \\
\hline Compression Ratio & $12.5: 1$ \\
\hline Type of control unit & Electronic control unit with control driver \\
\hline Fuel System & EFl (electronic fuel injection) \\
\hline Throttle Body Assy & Single throttle valve (bore $43 \mathrm{~mm})$ \\
\hline Fuel Injector & Fine atomizing type with 10 holes \\
\hline Ignition System & Digital DC-CDI \\
\hline Timing Advance & Electronically advanced \\
\hline
\end{tabular}

The motorcycle control software, together with a calibration set, enables not only download of data fields but also their editing in an acceptable range by means of the modification software. It is necessary to create an adequate link between the control unit and modification element in order to obtain an access to control information. That is enabled using diagnostic interface. In this specific case the modification element is the computer equipped with a corresponding software product and with drivers of motorcycle devices [6]. Downloading of reference serial data requires an interconnection of the motorbike control unit with the calibration set by means of data cables and by means of the supplementary driver of control unit. At the same time it is necessary to provide external source of $\mathrm{DC}$ voltage $12 \mathrm{~V}$. After removing of protective cover a cable bundle of the supplementary driver was connected with an output connector of the control unit by means of a data connector. The next step was to connect a $12 \mathrm{~V}$ accumulator with an output cable of a capacitor and then to connect the data cable of the supplementary driver for the control unit with the computer.

\section{Proposal of individual fuel map}

One of the most important operational characteristics, for the electronic management system (EMS), is the realisation of fuel amount.

The main proposal of fuel injection is based predominately on an operational characteristic of four-stroke combustion engine, keeping the optimal composition of fuel mixture at all operational regimes.
The operational loading of a piston combustion engine is defined most often by a position of the throttle valve. This position is scanned using the TPS sensor. The loading range is expressed in percentage from 0 to 100 or by means of the angle value, which corresponds to the turning of the throttle valve and it is given in degrees [deg]. Another kind of the engine loading is defined by an underpressure, which is generated in a suction tract. The underpressure value is monitored using the MAP sensor and it is given in $[\mathrm{kPa}]$. Another correction parameter is information obtained from an accelerator position sensor, which determines backpedal intensity or rotation speed of gas handle. This sensor compares an actual position of an accelerator and a throttle valve. In the solved case the motorbike control unit works according to the standard data fuel map, which is based on an actual engine loading. This loading is expressed by means of throttle valve position and engine speed. Time interval of fuel injection depends on TPS sensor data and engine speed. Data fuel map is compiled using the above-mentioned data and the control unit is modifying a correction of fuel injection time interval taking into consideration actual operational conditions.

The control unit performs other unavoidable corrective modifications of opening time for injector in order to optimise this racing engine operation. The modifications are depended on the following parameters:

\section{$\checkmark$ engine coolant temperature (ECT), \\ $\checkmark$ intake air temperature (IAT), \\ $\checkmark$ value of manifold absolute pressure (MAP), \\ $\checkmark$ injector operation, \\ $\checkmark$ ignition system operation, \\ $\checkmark$ voltage state in supply system, \\ $\checkmark$ engaged speed gear.}

The proper tuning and determination of optimal fuel map require wide-range knowledge in the field of motormanagement and engine design. In this article there are presented two proposals of data fuel maps. The unleaded gasoline with octane number 100 was taken into consideration at ambient temperature between $20^{\circ} \mathrm{C}$ and $21^{\circ} \mathrm{C}$ for the compilation of fuel map $[7,8]$.

A proposal of optimal fuel map, which can be implemented into motormanagement accordingly, requires information about a suitable mixture composition and about a value of volumetric 
efficiency (VE) during all operational regimes. A volumetric efficiency, comparing the real and theoretical volume of intake air during suction stroke, is relevant with regard to determination of injection time.

The highest value of volumetric efficiency is in the case maximum torque and wide-open throttle (WOT) and therefore in this zone it is necessary to accommodate the time interval of open in injection valve.

The maximum value of the volumetric efficiency corresponds to the speed range from 6,800 to $7,400 \mathrm{rpm}$ and the standard maximum torque is $43 \mathrm{~N} \cdot \mathrm{m}$ at $6750 \mathrm{rpm}$ for the tested motorcycle. In the case of powerful single-cylinder ignition engines a volumetric efficiency is changing suddenly according to a change of actual operational loading. These kinds of combustion engines do not reach flatter torque characteristic. That is why it is substantial to process the values obtained from the sensor TPS and from the sensor MAP in a suction pipe as soon as possible. The motorcycle motormanagement operates with values of injection time, which is given in milliseconds [ms], however the modification software disposes with the injection time data expressed in percentage [\%] in order to modify a fuel map.

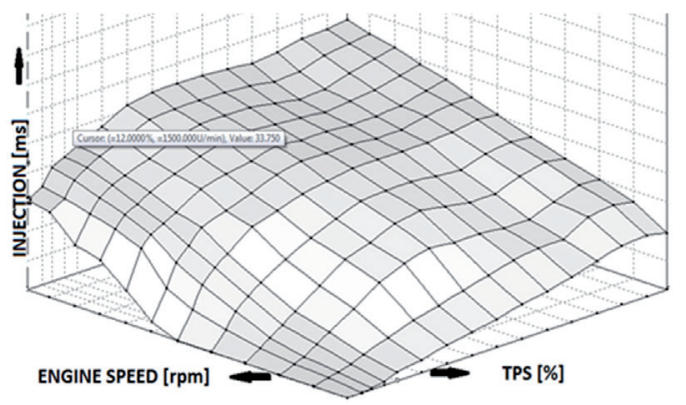

Fig. 3: The first version of a proposed data map for fuel injection.

In such cases the real motormanagement data map is derived as a distribution base for users's adjustments and it is implemented into zeropercentage values. The injection system of the given motorbike is offered with the throttle diameter $43 \mathrm{~mm}$ and it operates with the 10-inlets solenoid injector.

Composition of an optimal fuel map requires information about the flow rate value through an injection nozzle and also information about the
Tab. 2: Fuel Map - Version 1 [ms].

\begin{tabular}{|l|l|l|l|l|l|l|}
\hline \multirow{2}{*}{$\begin{array}{l}\text { Throttle } \\
\begin{array}{l}\text { Position } \\
{[\%]}\end{array}\end{array}$} & \multicolumn{6}{l}{ Engine speed [rpm] } \\
\cline { 2 - 7 } & $\mathbf{2 0 0 0}$ & $\mathbf{4 0 0 0}$ & $\mathbf{6 0 0 0}$ & $\mathbf{8 0 0 0}$ & $\mathbf{1 0 0 0 0}$ & $\mathbf{1 2 0 0 0}$ \\
\hline 0 & 1.35 & 1.01 & 0.91 & 0.80 & 0.81 & 0.80 \\
\hline 10 & 3.30 & 2.94 & 2.51 & 2.47 & 2.26 & 2.26 \\
\hline 20 & 5.51 & 4.58 & 3.50 & 3.43 & 3.40 & 3.40 \\
\hline 30 & 5.70 & 5.05 & 4.98 & 4.96 & 4.26 & 4.26 \\
\hline 40 & 5.99 & 5.16 & 6.06 & 6.40 & 5.67 & 5.80 \\
\hline 60 & 6.30 & 5.80 & 6.50 & 7.50 & 7.01 & 7.05 \\
\hline 80 & 6.40 & 5.84 & 6.88 & 7.96 & 7.37 & 7.5 \\
\hline 100 & 6.46 & 5.86 & 6.91 & 7.96 & 7.9 & 7.55 \\
\hline
\end{tabular}

pressure in a fuel system. The applied fuel injector has got the over-dimensioned flow capacity $0.291 \mathrm{l} / \mathrm{min}$ and the operational pressure in the fuel system is $297 \mathrm{kPa} \pm 3.5 \%$. A pressure correction of the fuel system is controlled by means of the individual data field with a correction coefficient $[9,10]$.

The flow capacity of an injection nozzle is an important parameter for an injection time setting. In order to determine the injection time interval it is applied the pulse time, which also covers an injector-opening interval. An operation of the injector is described by the pulse period, which determines times of injection valve opening and then closing. A length of pulse period is depended on increasing of engine speed and the injection time is accommodated according to this period. The opening time is also a function of supply voltage. The system supply voltage for the given motorcycle is from the interval $11.8 \div 14.2 \mathrm{~V}$ according to its operational loading. The opening time of injection valve is between $0.8 \div 1.1 \mathrm{~ms}$ for the stable voltage.

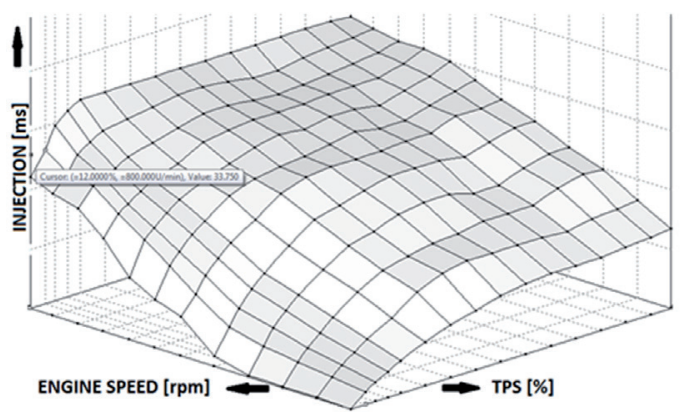

Fig. 4: The second version of a proposed data map for fuel injection. 
Tab. 3: Fuel Map - Version 2 [ms].

\begin{tabular}{|l|l|l|l|l|l|l|}
\hline \multirow{2}{*}{$\begin{array}{l}\text { Throttle } \\
\text { Position } \\
{[\%]}\end{array}$} & \multicolumn{6}{|l|}{ Engine speed [rpm] } \\
\cline { 2 - 7 } & $\mathbf{2 0 0 0}$ & $\mathbf{4 0 0 0}$ & $\mathbf{6 0 0 0}$ & $\mathbf{8 0 0 0}$ & $\mathbf{1 0 0 0 0}$ & 12000 \\
\hline 0 & 1.15 & 0.94 & 0.71 & 0.71 & 0.71 & 0.71 \\
\hline 10 & 3.27 & 2.84 & 2.46 & 2.27 & 2.06 & 2.06 \\
\hline 20 & 5.11 & 4.08 & 3.26 & 3.29 & 3.02 & 3.04 \\
\hline 30 & 5.50 & 4.80 & 4.07 & 4.09 & 3.64 & 3.66 \\
\hline 40 & 5.71 & 5.11 & 4.93 & 4.86 & 4.36 & 4.36 \\
\hline 60 & 5.99 & 5.16 & 6.06 & 6.40 & 5.67 & 5.80 \\
\hline 80 & 6.11 & 5.24 & 6.38 & 7.36 & 6.7 & 6.7 \\
\hline 100 & 6.06 & 5.26 & 6.41 & 7.70 & 7.4 & 7.1 \\
\hline
\end{tabular}

The most of serial engine control systems operates with feedback algorithm of lambda regulation, i.e. with the so-called "closed loop" regime. This operational regime is specific because it respects the target values of a ratio between air and fuel. The racing engines are exposed to permanent operational changes and they work without the processing of actual values obtained from the lambda regulation. It is the so-called "open loop" regime where the $\lambda$-values are not processed by the motormanagement and the engine works in this regime without a correction of the lambda regulation data field $[11,12]$.

This advantageous regime of the controlled injection enables an immediate enriching of fuel mixture during the maximum acceleration without an evaluation of the optimal mixture composition. The ideal mixture composition for the singlecylinder four-stroke racing ignition engine is reached at the enriched regime. All these aspects were taken into consideration during a composition of the first version of the modified fuel map (Fig. 3 and Tab. 2).

A downline of the first version of the edited fuel map into the motorcycle control unit was realised by means of the linked communication interface. After starting of the engine, when the working temperature reached the operational value (min. $75^{\circ} \mathrm{C} \div 80^{\circ} \mathrm{C}$ ), the optimal values of the $\lambda$-ratio were determined using the additive output of the mixture richness at the dynamometer. The lambdavalues were recorded in the range from the idling speed to the intervention of a speed limiter. A suitability of fuel mixture was evaluated during individual operation loading areas. The first variant of a fuel map was specified into the enriched area and after the evaluation of mixture composition, during measurement, there was the concrete part of the data field corrected. The more relevant deviation was recorded in the speed range from 6,300 to $8,100 \mathrm{rpm}$. In this speed interval there is an area of maximal volumetric efficiency (VE) situated and from this reason it is necessary to ensure the corresponding fuel delivery. The injection time interval was shortened in the middle speed area, because it was monitored that the fuel mixture is enriched at the values from the $\lambda=0.81$ to 0.84 in the framework of the speed range between 6,250 and 7,400 rpm. The fuel delivery was reduced about $5 \div 8 \%$ during a proposal of the second version fuel map (Fig.4 and Tab. 3) and in this way the mixture composition value was modified to the level $\lambda=0.90 \div 0.93$ in the middle speed range.

After the application of data field modified versions there was a set of the detail control measuring performed using the cylindrical power output dynamometer.

\section{The verification of obtained results}

The most relevant step for the motormanagement modifications is a determination of power output and torque parameters. The feedback verification of modification influence on the data field is important for an adjusting of the motormanagement modification accuracy.

Every more substantial modification of the control unit operation develops adequate changes. From this reason the best monitoring method of the performed changes is a measuring of the combustion engine characteristic using the poweroutput dynamometer. The cylindrical dynamometer was applied in order to verify an accuracy of data field modifications that were performed for an injection and for an ignition advance. The applied cylindrical dynamometer is one of the most modern power-output dynamometers used for a testing of single-track vehicle parameters. The complex testing stand is equipped with an additive highefficiency ventilation device and with an exhaustion of exhaust gas. This supplementary equipment enables to create optimal working conditions as well as to make possible the additional cooling of loaded engine.

The dynamometric equipment is able not only to measure the power output and torque but also a fuel mixture composition $(\lambda)$, a temperature of the 


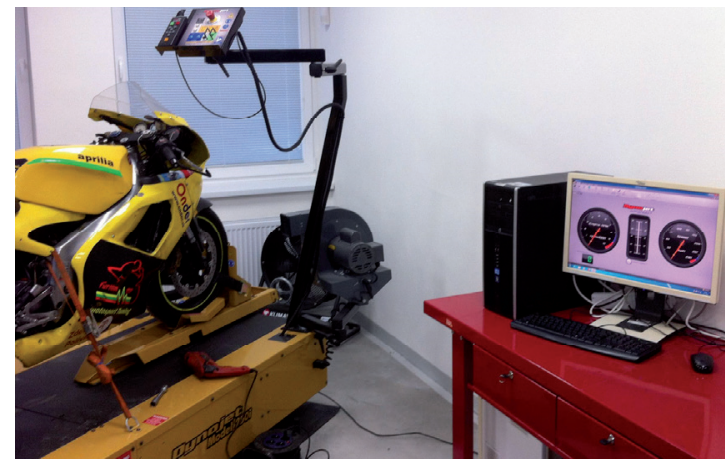

Fig. 5: The anchorage of racing motorcycle to the dynamometer.

cooling liquid, an engine speed and an operational loading. The dynamometer is able to measure power-outputs up to $560 \mathrm{~kW}$ and the maximum speed of the braking cylinder is $323 \mathrm{~km} \cdot \mathrm{h}^{-1}$.

In order to recalculate the output parameters the software of a dynamometer operates with the standards JIS, DIN, SAE J 1349, STD and EEC. Our measurement was performed according to the German national standard DIN 70020, which deals with a measuring using the complete engine equipment and it allows the deviation of power output parameters $\pm 0.95 \%$ and the engine speed deviation $\pm 0.47 \%$. A change of the tested engine loading is reached by the regulation of excitation current, which controls a magnetic field magnitude between the rotor and the stator. The measuring stand disposes with own pneumatic circuit in order to ensure a proper function of the whole dynamometric system.

Accuracy and safety of measuring process requires a stable fixing of the tested motorcycle to the measuring dynamometer (Fig. 5). The fixing consists of a side anchorage of motorcycle frame to the dynamometer corpus by means of the tightening straps. The front motorcycle wheel is fixed to the static support. The supporting mechanism of the front wheel has got the holding side supports, which hold a stable wheel position. An ideal position of the motorbike is setup in such way that a vertical axis of the rear wheel is identical one with the centre of braking cylinder. It is important to keep the atmospheric condition as stable as possible due to objectiveness of the performed measurements according to the Tab. 4.

The balanced real wheel and an application of a smooth tire tread pattern are important for the correct measuring process. In order to perform the
Tab. 4: Atmospheric Conditions.

\begin{tabular}{|l|c|c|c|}
\hline \multirow{2}{*}{-} & \multicolumn{3}{|c|}{ Atmospheric Conditions } \\
\cline { 2 - 4 } & $\begin{array}{c}\text { Temperature } \\
{\left[{ }^{\circ} \mathbf{C}\right]}\end{array}$ & $\begin{array}{c}\text { Pressure } \\
{[\mathrm{Pa}]}\end{array}$ & $\begin{array}{c}\text { Humidity } \\
{[\%]}\end{array}$ \\
\hline $\begin{array}{l}\text { Range of values during the } \\
\text { measurement }\end{array}$ & $20.2 \div 20.9$ & 96.89 .103 & $52 \div 55$ \\
\hline
\end{tabular}

complex measuring of all monitored values it is necessary to connect a temperature wick-sensor of coolant to the cooler surface, as well as to connect the engine speed sensor and the sensing pipe for monitoring of exhaust gas composition. Before the start of a testing it is necessary to activate the exhaustion equipment togetherwith the ventilationcooling device and with the dynamometric control software. The required operation temperature of the tested engine is $85^{\circ} \mathrm{C}$ during each measuring. There was the fifth longest speed gear applied, because it enables to reach also the maximum speed value of the used secondary gear.

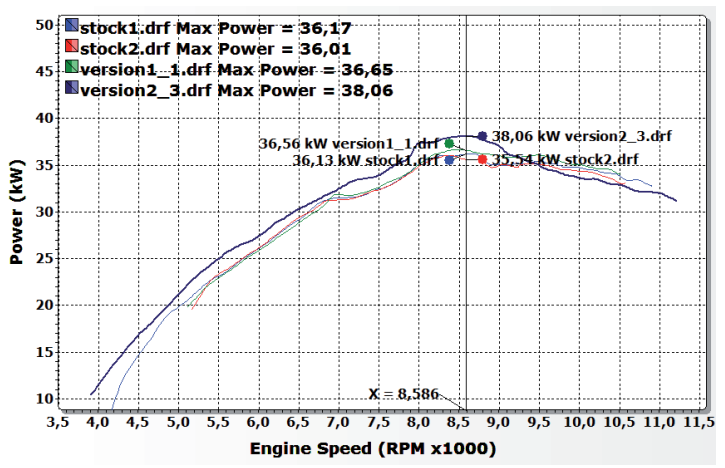

Fig. 6: The power output characteristic corresponding to the tested versions of the fuel maps.

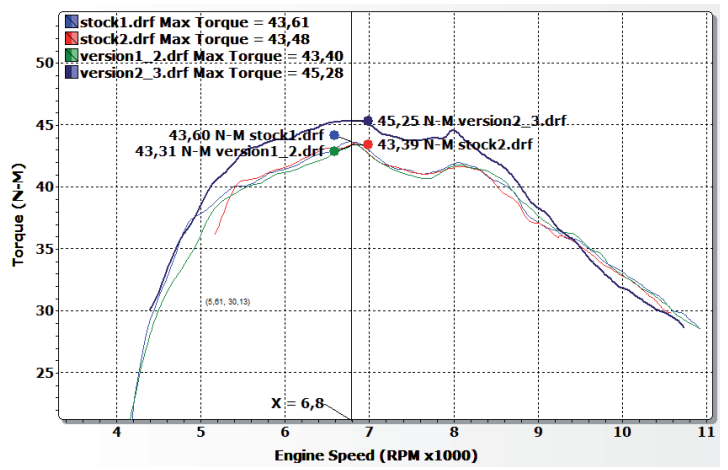

Fig. 7: The torque characteristic corresponding to the tested versions of the fuel maps. 


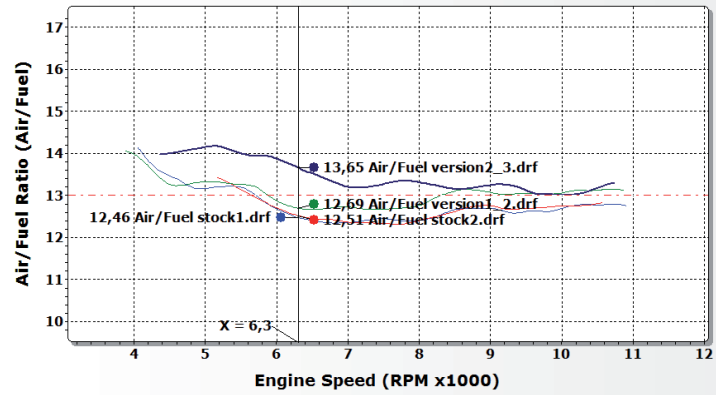

Fig. 8: The output air/fuel ratio characteristic of mixture composition (AFR) corresponding to the tested versions of the fuel maps.

Our detailed testing of the driving unit required to perform four measuring sequences, namely: serial measuring No.1, serial measuring No.2, measuring of the first version of the modified fuel map and measuring of the second version of the modified fuel map.

During all realized measurements there were monitored the operational parameters simultaneously by means of a data interlink. All the measured power output and torque values are recorded according to the technical standard DIN 70020 and they represent values obtained at the rear wheel, without a conversion to the values of a crankshaft output. The first measuring series was performed using an original set up of data fields, which were configured by the producer. We analysed two concrete measuring with the serial set up (Stock1 and Stock2) in order to obtain objective results. The values of the engine power output (Fig. 6), the torque (Fig. 7) and the mixture composition were monitored in relation to the engine speed (Fig. 8).

After a cooling down of the engine to the optimal temperature the experiment was finished and the next step was to connect the calibration set with the $12 \mathrm{~V}$ accumulator. In this way it is possible to exchange the serial data fields for the individually generated data fields related to a fuel injection and to an ignition advance. The following series of the next five measurements with using of the first modified fuel map version was performed after reheating of the engine. Downloading of the measured parameters and stopping of the engine finished the measuring process. The second version of the corrected fuel map was implemented into the control unit after a detailed analysis of the output characteristic obtained from the first version of the fuel map. Following another control measuring series was carried out. The increment of the maximum power output value was $2.05 \mathrm{~kW}$ and torque value was $1.8 \mathrm{Nm}$. These increments were achieved by using of the individual data fields for a fuel injection. That increased values of the tested parameters were observed during the second version of the modified fuel map.

A desired increasing of the power output was registered in the speed spectrum between the 7,000 rpm and 9,000 rpm (Fig. 6). In Fig 7 there is illustrated that an increased torque is available in the wide range of the applicable speed, namely from the 5,000 rpm to 9,000 rpm. The monitored increasing of the power output and torque is a positive phenomenon with regard to an application of the tested driving unit on real conditions of racing circuit. During the measuring of the second version there was the fuel mixture composition (the air/fuel ratio, AFR) optimised. Together there was the braking cylinder acceleration of the power-output dynamometer intensified as well as there was the throttle valve reaction accelerated.

The last two analysed characteristics describe engine flexibility and its acceleration ability. In the Fig. 9 there is a record of the engine speed values obtained during the time unit. In this case that time unit is defined by four seconds. Using the most suitable second version of the fuel map it was reached the engine speed value 9,350 rpm during the first four measured seconds, whilst the serial version application reached the speed value $9,000 \mathrm{rpm}$. The engine speed limiter intervened at the speed level 10,710 rpm after the measuring time $5.8 \mathrm{sec}$.

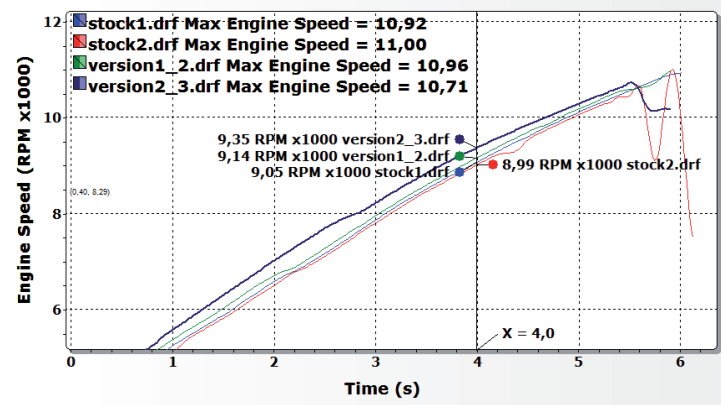

Fig. 9: Time behaviour characteristic of the brake cylinder acceleration in relation to the engine speed. 
Tab. 5: Measurement results.

\begin{tabular}{|l|l|l|l|l|l|}
\hline & $\begin{array}{c}\text { Maximum Output/ } \\
\text { Engine Speed } \\
{[\mathrm{kW} / \mathrm{rpm}]}\end{array}$ & $\begin{array}{c}\text { Maximum Torque/ } \\
\text { Engine Speed } \\
{[\mathrm{N} \cdot \mathrm{m} / \mathrm{rpm}]}\end{array}$ & $\begin{array}{c}\text { AFR at 6300 } \mathrm{rpm} \\
{[-]}\end{array}$ & $\begin{array}{c}\text { Rpm after 4 seconds } \\
\text { of the measuring } \\
{[\mathrm{rpm}]}\end{array}$ & $\begin{array}{c}\text { Velocity after 3 seconds of } \\
\text { the measuring } \\
{\left[\mathrm{km} \cdot \mathbf{h}^{-1}\right]}\end{array}$ \\
\hline 1. Stock1 & $36.17 / 8500$ & $43.61 / 6780$ & 12.46 & 9050 & 105.94 \\
\hline 2. Stock2 & $36.01 / 8450$ & $43.48 / 6800$ & 12.51 & 8990 & 107.05 \\
\hline 3. Version 1 & $36.65 / 8490$ & $43.40 / 6870$ & 12.69 & 9140 & 108.28 \\
\hline 4. Version 2 & $38.06 / 8580$ & $45.28 / 6790$ & 13.65 & 9350 & 112.70 \\
\hline
\end{tabular}

The next analysis (Fig. 10) compares acceleration of the motorcycle at the 5th speed gear. The third second of measuring was used for a record of the vehicle velocity. The tested motorbike, equipped with the second version of the fuel map, reached the velocity $112.70 \mathrm{~km} \cdot \mathrm{h}^{-1}$ whereas in the case of the serial set up the reached velocity value was $107 \mathrm{~km} \cdot \mathrm{h}^{-1}$.

All the evaluated and key parameters obtained from the examined versions of the fuel maps are presented in the Tab. 5. After installation of the modified data map a more cultivated running, better flexibility and improved acceleration characterize the experimental driving unit.

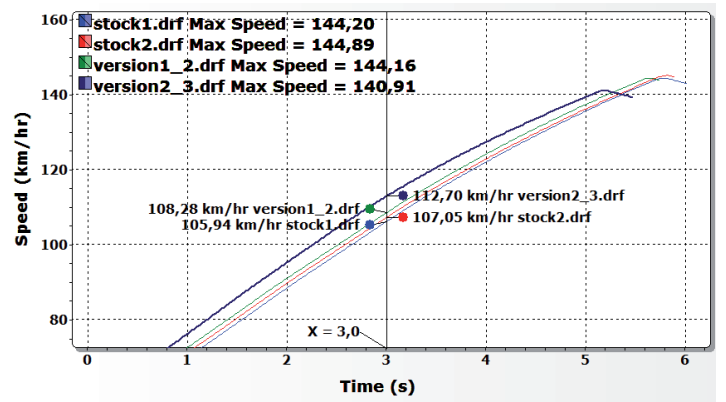

Fig. 10: Time behaviour characteristic of the brake cylinder acceleration in relation to the motorbike speed.

\section{Conclusions}

After a detailed analysis of the performed measurements it is possible to say that the proposed final data map of the fuel injection has got a positive influence on increase of driving unit output parameters. The time behaviour of realised measurements using the complex stand of cylindrical dynamometer confirms a fact that after application of the modified fuel map there is an increase of the power output and torque.

The characteristic of torque behaviour shows a continuous increase of the torque values in a wide speed range. This factor is important for application of this driving unit in real conditions. The control measurements also verified an improved possibility of the driving unit to react on a changing loading as well as to react more flexible according to a throttle valve opening. The last two examined characteristics illustrate an improved acceleration ability of the driving unit. The motorbike acceleration was more intensive during the given time interval. The modifications of the fuel injection data fields stabilised values of a mixture composition (air/fuel ratio, AFR). The recorded increase of the output parameters for the examined driving unit of the racing motorbike has got a positive influence on the application possibility in real racing circuit conditions.

The uncertainty analysis for measurements has been executed and expanded uncertainties have been determined for measurement results (tab. 3). Expanded uncertainty for maximum power output has value $0.45 \mathrm{~kW}$. Expanded uncertainty for torque has value $0.4 \mathrm{Nm}$. Measurement of engine speed has expanded uncertainty $5.5 \mathrm{rpm}$. Measurement of the air/fuel ratio (AFR) has expanded uncertainty 0.12 . The reported expanded uncertainties of measurement are stated as the standard uncertainties of measurement multiplied by the coverage factor $k=2$, which for a normal distribution corresponds to a coverage probability of approximately $95 \%$. The standard uncertainties of measurement have been determined in accordance with EAL Publication EAL-R2, EA-4/02 and JCGM 104:2009.

\section{Acknowledgments}

This work was supported by the Slovak Research and Development Agency under the contract No. APVV-16-0259.

The article was written in the framework of Grant Projects: APVV-16-0259 "Research and development of combustion technology based on controlled homogenous charge compression ignition in order to reduce nitrogen oxide emissions of motor 
vehicles", VEGA 1/0473/17 "Research and development of technology for homogeneous charge self-ignition using compression in order to increase engine efficiency and to reduce vehicle emissions" and KEGA 041TUKE-4/2017 "Implementation of new technologies specified for solution of questions concerning emissions of vehicles and transformation of them into the educational process in order to improve quality of education."

\section{References and Notes}

[1] PUŠKÁR, M.; BIGOŠ, P.: Method for accurate measurements of detonations in motorbike high speed racing engine, Measurement 2012, Vol. 45, no. 3 (2012), p. 529-534, ISSN 0263-2241

[2] PUŠKÁR, M.; BIGOŠ, P.; PUŠKÁROVÁ, P.: Accurate measurements of output characteristics and detonations of motorbike high-speed racing engine and their optimization at actual atmospheric conditions and combusted mixture composition, Measurement 2012, Vol. 45, no. 5 (2012), p. 1067-1076, ISSN 0263-2241

[3] PUŠKÁR, M.; BIGOŠ, P.; BALÁŽIKOVÁ, M.; PEŤKOVÁ, V.: The measurement method solving the problems of engine output characteristics caused by change in atmospheric conditions on the principle of the theory of optimal temperature range of exhaust system, Measurement 2012, In Press, ISSN 0263-2241

[4] PUŠKÁR, M. ... [et al.]: Measuring method for feedback provision during development of fuel map in hexadecimal format for high-speed racing engines, In: Measurement. Vol. 50, no. 1 (2014), p. 203-212. - ISSN 0263-2241

[5] Hiroyuki Yamada, Rumiko Hayashi, Kenichi Tonokura : Simultaneous measurements of on-road/in-vehicle nanoparticles and NOx while driving: Actual situations, passenger exposure and secondary formations, Science of The Total Environment, Volumes 563-564, 1 September 2016, Pages 944-955

[6] Xiangyu Feng, Yunshan Ge, Chaochen Ma, Jianwei Tan, Xin Wang: Experimental study on the nitrogen dioxide and particulate matter emissions from diesel engine retrofitted with particulate oxidation catalyst, Science of The Total Environment, Volume 472, 15 February 2014, Pages 56-62

[7] PUŠKÁR, M., BRESTOVIČ, T., JASMINSKÁ, N. Numerical simulation and experimental analysis of acoustic wave influences on brake mean effective pressure in thrust-ejector inlet pipe of combustion engine. In: International Journal of Vehicle Design. Vol. 67, no. 1 (2015), p. 63-76. - ISSN 01433369

[8] SINAY, J. et al. (2014) Multiparametric Diagnostics of Gas Turbine Engines. The Transactions of RINA, Vol 156, Part A2, International Journal of Maritime Engineering, 2014, p. 149156, ISSN 1479-8751
[9] Balland, O.; Erikstad S. O.; Fagerholt, K.: Concurrent design of vessel machinery system and air emission controls to meet future air emissions regulations, Ocean Engineering, Volume 84, 1 July 2014, Pages 283-292

[10] PUŠKÁR, M.; BIGOŠ, P.: Output Performance Increase of Twostroke Combustion Engine with Detonation Combustion Optimization, Strojarstvo 2010: Vol. 52, no. 5 (2010), p. 577587, ISSN 0562-1887

[11] PUŠKÁR, M.; BIGOŠ, P. Measuring of acoustic wave influences generated at various configurations of racing engine inlet and exhaust system on brake mean effective pressure, Measurement 46 (9) (2013) 3389-3400. ISSN 0263-2241.

[12] Czech P. Application of probabilistic neural network and vibration signals for gasket under diesel engine head damage. Scientific Journal of Silesian University of Technology. Series Transport. 2013. Vol. 78. P. 39-45. ISSN: 0209-3324

\section{Biographical notes}

doc. Ing. Michal Puškár, PhD.: Is a researcher at the Department of Engineering for Machine Design, Automotive and Transport at the Faculty of Mechanical Engineering, Technical University of Kosice. He graduated at the mentioned Department in 2005 and the PhD.-degree received in 2008 with theme of his dissertation thesis: Rising of Power Parameters of Single-Track Transport Means. His current fields of research interest are single-track transport means, piston combustion engines and increasing of their power output and reliability.

Ing. Melichar Kopas, PhD.: Is an assistant lecturer at the Department of Engineering for Machine Design, Automotive and Transport at the Faculty of Mechanical Engineering, Technical University of Košice. He graduated at the Department of Transport and Handling Machines, which was a predecessor of the above-mentioned Department in 1988. The PhD.-degree he obtained with the dissertation thesis target on the theoretical and practical questions concerning the transport systems of bulk materials. His research activities are focused on the driving mechanisms and transmissions designed for the transport and handling machines or machineries as well as on the theory and construction of the mechanical conveyors for bulk solids.

Ing. Dušan Puškár: Is a PhD. student at the Department of Engineering for Machine Design, Automotive and Transport at the Faculty of Mechanical Engineering, Technical University of Košice. He graduated at the mentioned Department in 2016. His current fields of research interest are single-track transport means, piston combustion engines and increasing of their power output and reliability. 


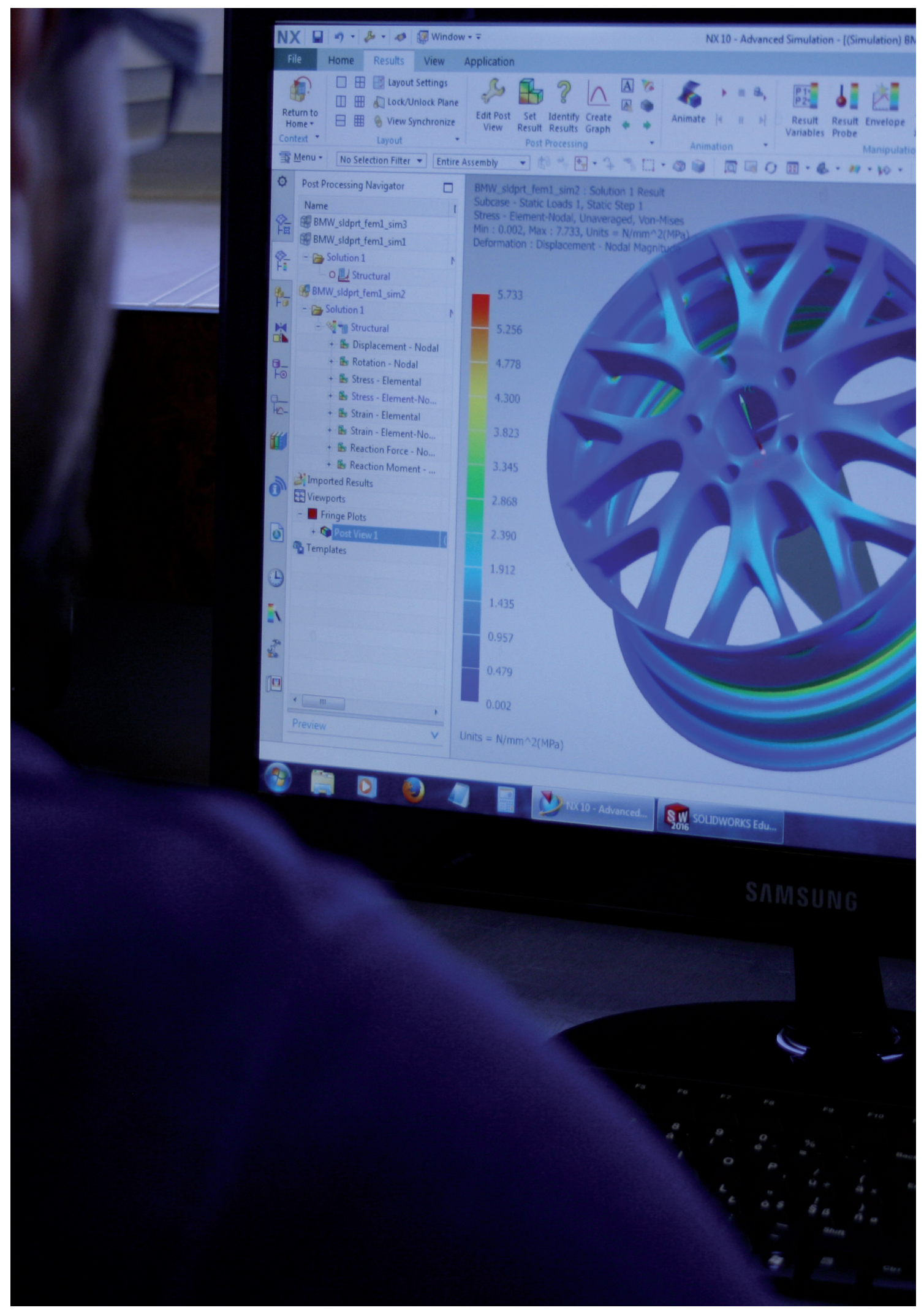

